
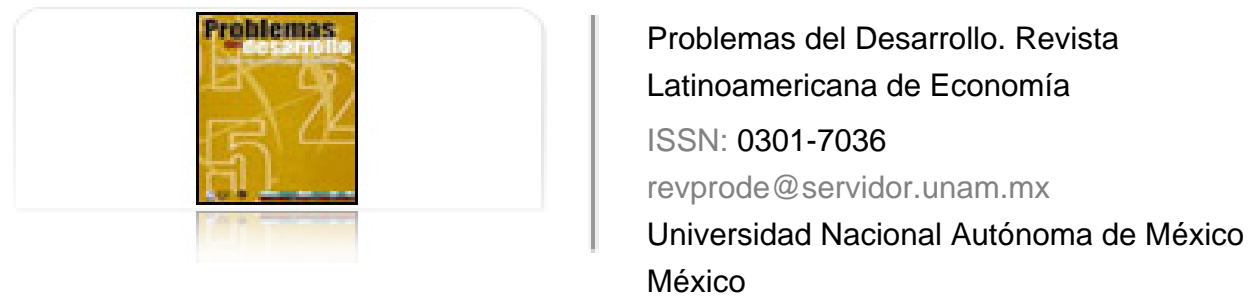

Cota Yáñez, María del Rosario

Estructura organizacional de las empresas de la confección de Zapotlanejo, Jalisco Problemas del Desarrollo. Revista Latinoamericana de Economía, vol. 35, núm. 138, 2004, pp. 155-

176

Universidad Nacional Autónoma de México

Distrito Federal, México

Disponible en: http://www.redalyc.org/articulo.oa?id=11825948008

Cómo citar el artículo

- Número completo

- Más información del artículo

Página de la revista en redalyc.org

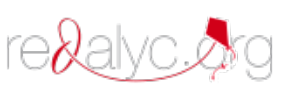

Sistema de Información Científica

Red de Revistas Científicas de América Latina, el Caribe, España y Portugal Proyecto académico sin fines de lucro, desarrollado bajo la iniciativa de acceso abierto 


\section{ESTRUCTURA ORGANIZACIONAL DE LAS EMPRESAS DE LA CONFECCIÓN DE ZAPOTLANEJO, JALISCO}

\section{María del Rosario Cota Yáñez*}

Fecha de recepción: 10 de noviembre de 2003. Fecha de aceptación: 24 de agosto de 2004

\section{Resumen}

Sin lugar a dudas, Zapotlanejo, Jalisco representa un ejemplo ilustrativo del surgimiento y desarrollo de las iniciativas locales para llevar a cabo el desarrollo económico a partir del surgimiento y desarrollo de una actividad económica, en este caso la confección de prendas de vestir para dama. La fabricación de prendas de vestir en la localidad generó la configuración de diversas zonas de influencia expresadas principalmente en el asentamiento de microempresas, la comercialización y se ha constituido un mercado laboral.

Palabras clave: distritos industriales, confección, desarrollo económico local.

\section{Abstract}

Undoubtedly, Zapotlanejo, Jalisco, represents an illustrative example of the emergence and development of local initiatives for carrying out economic development based on the emergence and development of an economic activity -in this case, ladies' apparel. The apparel industry in the locality generated a configuration of several zones of influence expressed mainly in the establishment of micro-companies and marketing, and the constitution of a labor market.

Key words: industrial districts, apparel, local economic development.

* Departamento de Estudios Regionales (DER) del Instituto de Estudios Económicos y Regionales (INESER), Universidad de Guadalajara. Correo electrónico: macotaya@cucea.udg.mx 


\section{Résumé}

Sans aucun doute, Zapotlanejo, Jalisco, représente un exemple illustratif du surgissement et du développement des initiatives locales pour mener à bien le développement économique à partir du surgissement et du développement d'une activité économique, dans ce cas, la confection d'habits pour dames. La fabrication de vêtements dans la localité a généré la configuration de diverses zones d'influence exprimées principalement par l'installation de micro entreprises, par la commercialisation ainsi que par la constitution d'un marché de travail.

Mots clés : Districts industriels, confection, développement économique local.

\section{Resumo}

Sem dúvidas, Zapotlanejo-Jalisco representa um ilustrativo exemplo do aproveitamento de iniciativas locais para realizar o desenvolvimento econômico a partir do incentivo e crescimento de uma atividade econômica. Neste caso, a confecção de peças de vestuário feminino. A fabricação de peças de vestuário na localidade gerou a configuração de diversas zonas de influência, expressas principalmente pelo assentamento de microempresas, estabelecimento de relações comerciais e pela constituição de um mercado de trabalho.

Palavras-chaves: distritos industriais, confecção, desenvolvimento econômico local. 


\section{Introducción}

$\mathrm{E}$

1 desarrollo económico local representa un factor importante a la hora de rencia de los planes y programas públicos de fuera. Las formas de organización en espacios altamente especializados de microempresas funcionan con base en sus propias estrategias de sobrevivencia, ante las recurrentes crisis por las que han pasado las industrias mexicanas en los últimos veinte años. A pesar de lo anterior, se pueden observar hoy localidades que presentan un inusitado crecimiento económico y que ponen a la luz del debate elementos estudiados acerca de los distritos industriales.

El objetivo del presente trabajo es analizar las formas de organización y estrategias de crecimiento que experimentan los productores de ropa para dama en una región altamente especializada. El análisis se centra en la fabricación de ropa de la localidad de Zapotlanejo, Jalisco.

La hipótesis que guía el estudio habla de cómo están creando sus propias estrategias de crecimiento económico, sustentadas en algunas características del modelo de los distritos industriales. La metodología se apoya en el uso de fuentes directas e indirectas. Se hicieron entrevistas a los principales actores del desarrollo industrial de la localidad. También se buscó información de fuentes oficiales.

El documento se encuentra dividido en tres partes: en la primera se retoman elementos conceptuales de los distritos industriales, con el fin de explicar algunos de los procesos que ocurren en la localidad, a raíz de un eje rector: la industria de la ropa. El segundo apartado hace un recuento histórico acerca de la transformación de base económica y, por último, se presentan las estrategias adoptadas por los empresarios para enfrentar la competencia hoy en día.

\section{El desarrollo económico local a la luz de consideraciones teórico-metodológicas}

\section{El distrito industrial como forma explicativa}

La importancia de lo local ha aumentado. Lo que despierta mayor atención es que se altera lo que antes existía ${ }^{1}$ (Meyer-Stamer, 2000:19). Un ejemplo palpable de ello es la concepción del distrito industrial.

1 Rabelloti (1997:15-17) hace un exhaustivo análisis del desarrollo de los distritos industriales en Italia. Becattini (1989) estudia el desar rollo económico de las aglomeraciones industriales en Italia, 
Los procesos de descentralización productiva y la formación de redes constituidas por las pequeñas empresas especializadas encuentran su mejor expresión en ciertos territorios que, con el tiempo ha generado un efecto de aglomeración, según Caravaca (1998), ha favorecido el surgimiento de iniciativas locales.

Desde hace más de un siglo se había descrito el fenómeno conceptualizado mediante la aglomeración territorial de empresas del mismo ramo o ramos similares, en el cual hay mano de obra especializada, los insumos y prestación de servicios están fácilmente disponibles y las innovaciones se difunden con relativa facilidad. Estas cualidades no se habían considerado hasta que Becattini (1989) y otros autores, principalmente italianos, trajeron a la luz el concepto distrito industrial (DI) a partir de la crisis de los años setenta, debido a la inminente necesidad de encontrar nuevos medios para el desarrollo económico en países de industrialización tardía. Becattini (1989) retomó dicho término vertido en un principio por Marshall (1920), quien sostenía que en ciertos sectores productivos las ventajas de producción a gran escala pueden obtenerse no solamente de la concentración de producción en grandes establecimientos, sino también de la reunión de un mismo distrito de muchos pequeños productores encargados de la ejecución de una fase del proceso productivo (Becattini, 1989 y 1994:40). El principal argumento esbozado al respecto fue que las estructuras internas de los espacios locales presentaban un dinamismo inusitado en relación con las grandes metrópolis. Argumento que fue corroborado posteriormente por otros autores en otras disciplinas y diferentes estudios de caso (Porter, 1990; Rabelloti, 1997).

El análisis de Marshall (1920:IV,IX,25) se basa en el funcionamiento de economías externas e intenta demostrar que es posible alcanzar economías de escala no en función de la dimensión de una empresa en particular, sino del tamaño productivo de un sistema de empresas localizadas en un territorio. Trata de demostrar que un sistema de pequeñas empresas especializadas en distintas funciones de producción es resultado del proceso de división del trabajo y, por consecuencia, de la ampliación de extensión del mercado. Define distritos industriales como aglomeraciones específicas de muchas pequeñas empresas con características similares.

Estos distritos pueden funcionar de manera eficaz en la medida en que se beneficien de la interacción del conjunto de elementos que constituye el complejo social. Su análisis puede dividirse en tres puntos que se refieren a las ventajas de especialización, economías de intermediación y a la atmósfera industrial.

Las ventajas de las economías de especialización vienen dadas a partir de la disminución de costos unitarios de transporte que favorecen los procesos de especialización espacial. Es decir, las fases sucesivas de un proceso de producción podrán ser realizadas

presentes siempre en la zona. Benko y Lipietz (1994) explican que los distritos industriales se consideran espacios emergentes, contribuyendo así a la superación de la tradicional relación ruralagraria-atraso, situación que ha despertado el interés por el desarrollo local y la atención de los investigadores.

\section{Desartoris}


convenientemente a gran escala en localidades distintas y cercanas a la fábrica (Marshall, 1920:Iv,X,1-14).

Las economías externas de intermediación están vinculadas directamente a la aglomeración. En este aspecto Bellandi (1986:32) considera necesario tener en cuenta la comodidad del cliente para realizar una compra poco elevada, éste se dirigirá a la tienda más cercana; en cambio, cuando se trate de una compra importante, se tomará la molestia de visitar cada lugar de la ciudad donde sabe que se encuentran los establecimientos especializados.

Los mayoristas e industriales encuentran ventajas en la aglomeración de empresas que les suministran materias primas y maquinaria relacionada con la actividad que realizan. Cuando una persona está interesada en la compra de un producto nuevo, es conveniente examinar las alternativas de precio y calidad. Esta búsqueda directa la conduce a los lugares donde se lleva a cabo la producción y comercialización de los mismos.

Es por ello que el concepto de economías externas aplicado al distrito industrial debe reconsiderarse, ya que éste es un sistema industrial en el que las relaciones sociales y territoriales asumen un papel preponderante en la comprensión de relaciones interempresariales. Por eso, Bellandi (1986:36-37) sugiere utilizar el término economías de aglomeración, pues en él se engloban economías externas, tecnológicas, así como territoriales y sociales.

Marshall (1920:Iv,VI,9) considera decisivo para el funcionamiento del distrito industrial la existencia de una tradición artesanal, de un espíritu innovador y de flexibilidades en las relaciones sociales. Esta atmósfera industrial ${ }^{2}$ favorece la creación de aptitudes no sólo para el trabajo manufacturero sino también para la innovación. ${ }^{3}$ En ese sentido, cuando una industria escogió una localidad para ubicarse en ella, es probable que permanezca

2 Atmósfera industrial es un concepto metafórico - utilizado en un principio por Marshall- de finales del siglo XVII para definir el contexto social, cultural, ideológico, religioso, político, institucional, entre otros, que condiciona la forma de actuar de los empresarios y a la vez permite el florecimiento o estancamiento de las zonas don de existe una aglomeración de pequeñas y medianas empresas. Este término está presente en casi todos los trabajos de investigación sobre distritos industriales (véase Becattini, 1989, 1994; Saba, 1998; Canullo, 1998; Quintar y Gatto 1992 y otros más). A pesar de ser ambiguo y confuso, hasta la fecha no existe una definición que lo sustituya. La connotación de atmósfera se refier ea un "espacio al que se extienden las influencias de alguien o algo, 0 ambiente que los rodea", de acuerdo con el Diccionario de la Lengua Española.

3 Las personas que buscan trabajo acuden donde se encuentran las fábricas que necesitan de un trabajo especializado. Así mismo está demostrado que cuando existen grandes masas de trabajadores comprometidos en una actividad similar en un mismo lugar, unos adiestran a otros y esto va generando una acumulación de Know how especializado en el distrito industrial, al momento que crea en la zona una ventaja para la localización de empresas que tienen necesidad. En este sentido, argumenta Bellandi (1986:40), "la atmósfera no puede moverse", debido a lo que M arshall (1920, IV, X:7) dice: porque los secretos del oficio hasta se respiran en el aire y las generaciones futuras lo aprenden de forma innata. Aunque los autores mencionados consideran la no movilidad del espacio industrial, creo que sí son reproducibles algunas de las características más importantes en otros lugares. Es aquí donde entra la dicotomía imperante en los últimos años: ¿el distrito industrial nace o se hace? Habrá que seguir haciendo estudios para tratar de responder la pregunta. 
durante mucho tiempo, ya que obtiene ventajas por su ubicación y, a la vez, atrae otras actividades con las que se relaciona, como son tiendas distribuidoras de telas, cierres y maquinaria especializada.

Aunque en la literatura, el Di no es presentado como un modelo analítico, manifiesta una serie de consideraciones que pueden ser utilizadas dentro de la investigación empírica y confrontarse con esta realidad. El DI se puede definir en términos de cuatro elementos:

a) Formado por clusters de pequeñas y medianas empresas que están espacialmente concertadas y sectorialmente especializadas.

b) Existe una compleja red de relaciones comerciales, económicas y tecnológicas entre las empresas; utilizan la estrategia just in time y la subcontratación.

c) Influyen en ellas condiciones histórico-culturales y relaciones de confianza, en las cuales se pueden dar las alianzas formales e informales.

d) Existe apoyo del gobierno local mediante políticas de desarrollo.

Estas características son observadas por Becattini (1994), Crewe (1996) y Rabellotti (1997) en estudios clásicos de distritos italianos, en Baden-Wurttemberg (Alemania), Silicon Valley (Estados Unidos), Lace Market (Inglaterra). No existe una especialización única, sino que se desarrollan actividades tan diversas como la producción de textiles, calzado, confección, muebles de madera, juguetes, cerámica, componentes electrónicos, entre otros.

\section{Zapotlanejo ante la evidencia empírica}

De acuerdo con la literatura especializada, Zapotlanejo presenta elementos de los Di por medio de los cuales pudiera ser estudiado, específicamente, tomando en cuenta los tres primeros. Es una ciudad pequeña, con un alto grado de especialización, el cual le sirve a las actividades económicas de la confección de prendas de vestir, principalmente de dama. Existe una compleja red de relaciones sociales y el desarrollo de la actividad responde a cuestiones histórico-culturales. Su ubicación estratégica a un lado de la Zona Metropolitana de Guadalajara le brinda una posición de ventaja competitiva.

\section{a) Aglomeración y especialización}

En Zapotlanejo existe una aglomeración de actividades productivas en un espacio urbano identificado. Específicamente en la parte central de la localidad, la cual abarca 33 manzanas (véase Mapa 1). En dicho espacio se ubican 720 establecimientos dedicados a la fabricación y comercialización de ropa (Cota, 2004).

Actualmente existen cinco plazas: Centro Comercial Plaza Zapotlanejo, Vesti Plaza, Vesti Centro, Galerías del Sol y una de reciente apertura. Las cuatro primeras se encuen-

\section{Déparrorollo}




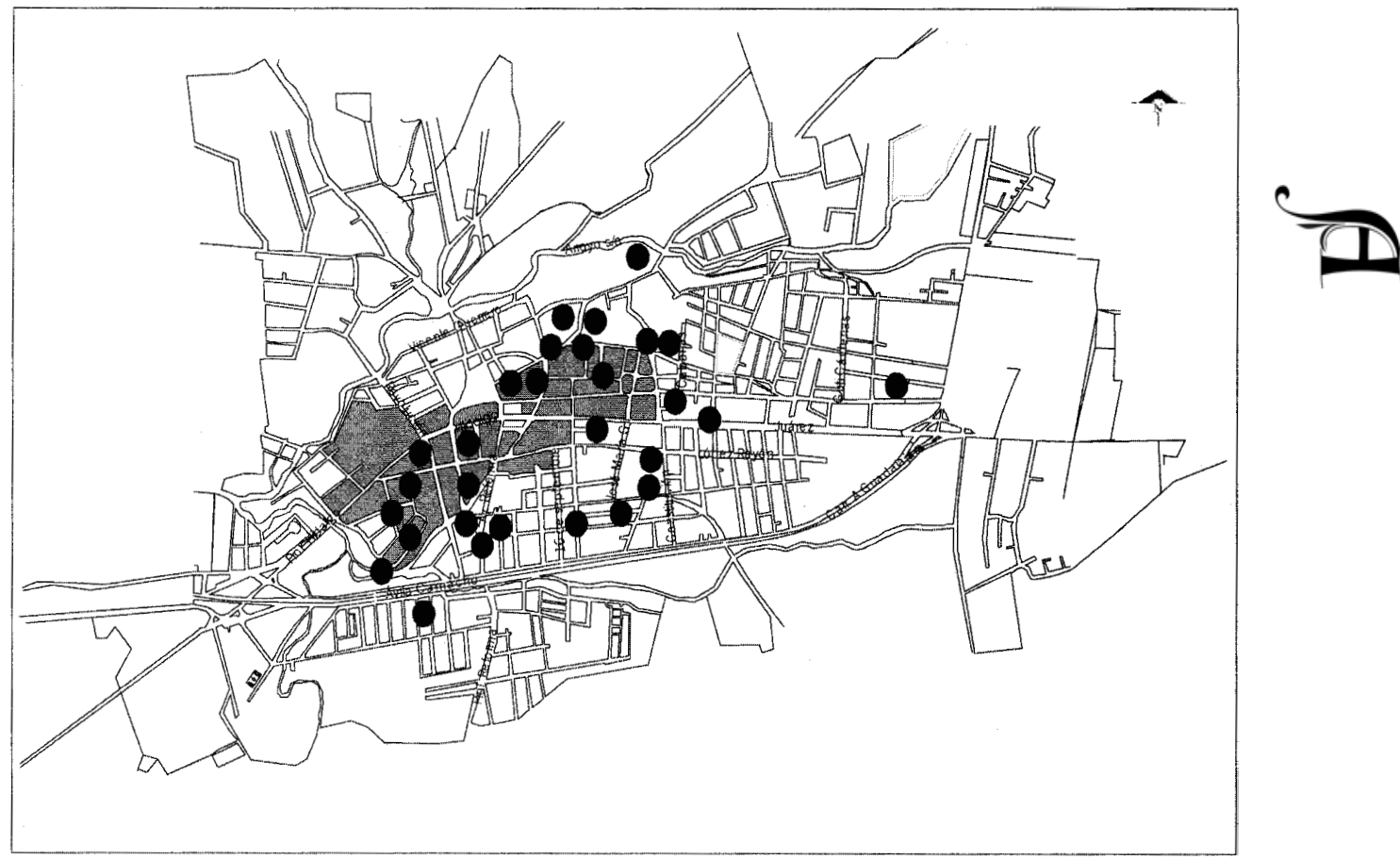

Mapa 1. Ubicación de las fábricas de ropa en Zapotlanejo, 2001.

Fuente: elaboración propia con base en el Directorio de la Expomoda, Zapotlanejo, 2001.

tran concentradas en un perímetro de cinco calles; la última se construyó a las afueras de la ciudad porque el espacio en el centro se encuentra saturado y se están generando deseconomías de escala como son las rentas de locales comerciales: un local de dos por tres metros de frente en la calle principal (Guadalupe) llega a costar de $\$ 80000$ hasta $\$ 100000$ al año; es decir, pagan en promedio $\$ 8000$ mensuales de renta. ${ }^{4} \mathrm{El}$ estacionamiento es un problema, en su parte céntrica, la ciudad está creciendo hacia arriba: se pueden ver construcciones a un lado de la plaza comercial de tres y cuatro pisos, lo cual, evidentemente contrasta con el paisaje urbano. Debido a los altos costos de las rentas, las dimensiones de los locales suelen ser cada vez menores.

Zapotlanejo está especializado en la fabricación de prendas de vestir, evidencia que se sustenta con datos del último censo económico realizado por el Instituto Nacional de Estadística Geografía e Informática (INEGI): para 1998, más de la mitad (63\%) de los establecimientos manufactureros se dedicaban a la fabricación de ropa; da empleo a $71 \%$ de los trabajadores de la industria (1 636); son microempresas que emplean en promedio a 7 empleados, cuyas remuneraciones anuales son aproximadamente de $\$ 14,220$, es decir, $\$ 39$ diarios.

4 Información proporcionada por los encargados de los mismos locales. 


\section{b) Compleja red de relaciones}

comerciales, económicas y tecnológicas

Dentro del DI se dan vínculos entre pequeñas empresas y habitantes del territorio, los cuales presentan características socioculturales adecuadas para un proceso de desarrollo de pequeñas empresas. Por ello se interpreta al distrito industrial como una densificación localizada, se puede ver como un gran complejo productivo, en el cual la coordinación entre las distintas fases del mismo y el control de su funcionamiento regular no se lleva a cabo mediante reglas preestablecidas, sino a través de una combinación del mercado y la sociedad.

Se presenta la característica de poder descomponer la producción en fases y la posibilidad de transportar en el espacio y el tiempo los productos; podría decirse que existe una fragmentación de la producción. Esto se debe a la peculiaridad que muestran industrias establecidas en un distrito, las cuales desarrollan una parte del proceso productivo y las partes que constituyen el producto se llevan a cabo en el espacio cercano. Los talleres que maquilan a las fábricas de Zapotlanejo se encuentran fuera de la localidad, pero dentro del municipio, y son principalmente las rancherías denominadas La Laja, Puente Grande, Santa Fe, Matatlán y La Joya (véase Mapa 2). También las encargadas de las tiendas y obreros se trasladan todos los días por autobús, cuyas salidas son cada 30 minutos a partir de las 6:00 am.

Lo anterior permite la existencia de una red de mercados locales de productos que en ella se elaboran y la subdivisión en el trabajo, dando oportunidad a la población de participar en múltiples labores. Prueba de ello es que los talleres de las rancherías se dedican a

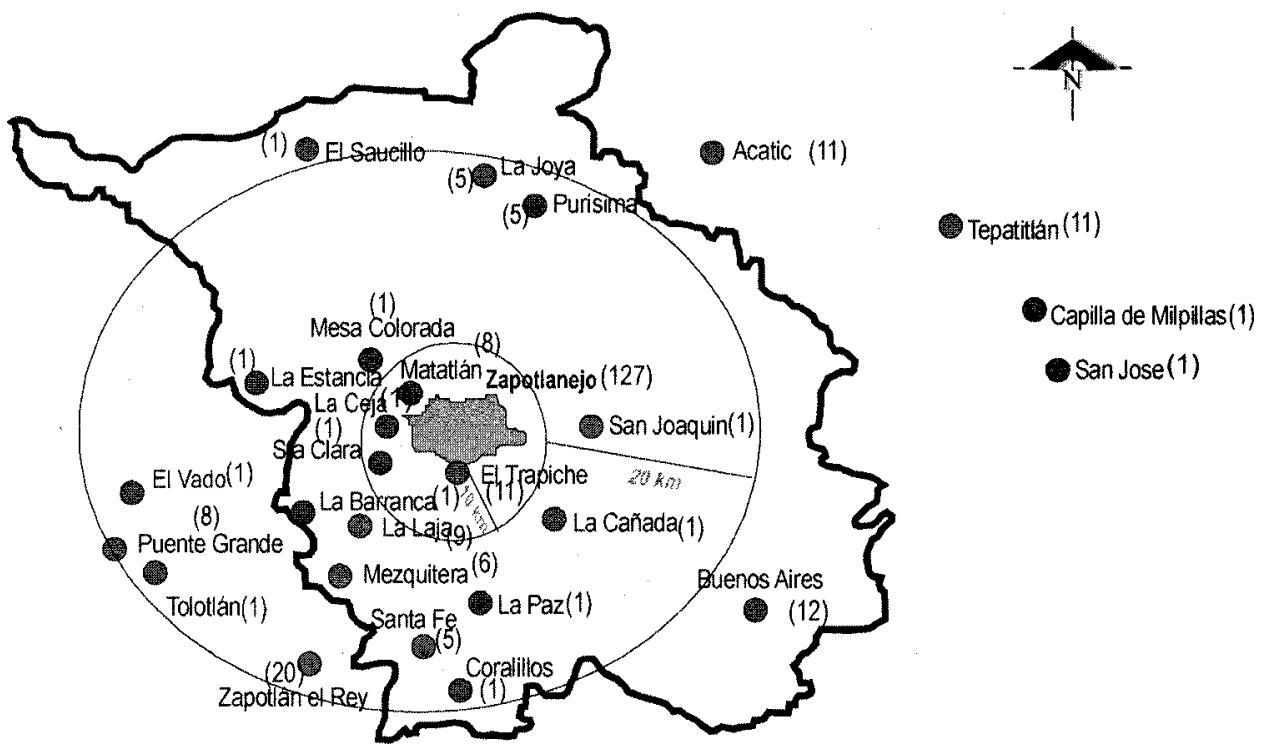

Mapa 2. Lugares de maquila domiciliar de los fabricantes de ropa, encuestados en Zapotlanejo, 2002.

Fuente: Encuesta de Reestructuración Productiva y Redes, Zapotlanejo, 2002. 


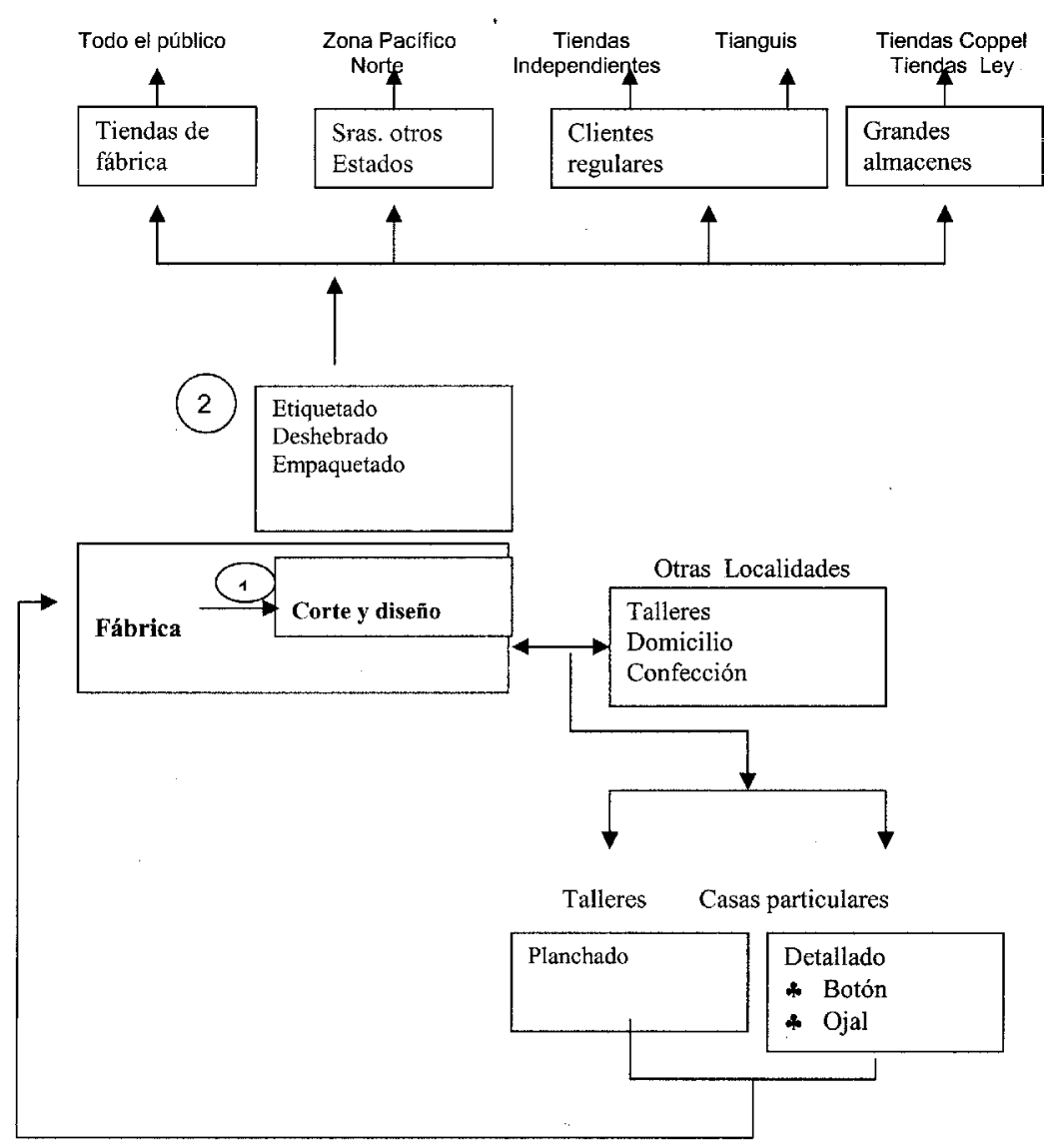

Esquema 1. Organización productiva, Zapotlanejo, 2002.

Fuente: $\quad$ elaboración propia a partir de la Encuesta de Reeestructuración Productiva y redes, Zapotlanejo, 2001.

la confección de la prenda y la fábrica de Zapotlanejo — dueña de las telas-, diseña, etiqueta, deshebra, plancha, comercializa y envía la mercancía (véase Esquema 1). La recepción de dichas prendas provenientes de los talleres lleva un estricto control y se revisan, una por una, todas las costuras. ${ }^{5}$

Existe una zona claramente definida dentro de la comercialización de ropa, la cual comprende los estados de Nayarit, Sinaloa, Sonora y Baja California Sur. Es en esta región donde señoras aboneras ${ }^{6}$ acuden regularmente a comprar. De igual forma las agencias de

5 Comentaba un gerente de una fábrica de camisas que lo hacen así para acostumbrar a la gente a trabajar con calidad y justo a tiempo, pues en un futuro tienen pensado incursionar en el mercado norteamericano. Este paso es importante, ya que en los mercados internacionales existen reglas muy estrictas en la confección, por ejemplo, las medidas entre las puntadas tienen que ser exactas y el manejo de la resistencia de los hilos.

$6 \quad$ La mayoría son mujeres cuyas edades fluctúan entre 25 y 40 años, y se dedican a comprar ropa de Zapotlanejo - acuden periódicamente en autobuses rentados exclusivamente para ello- y la 


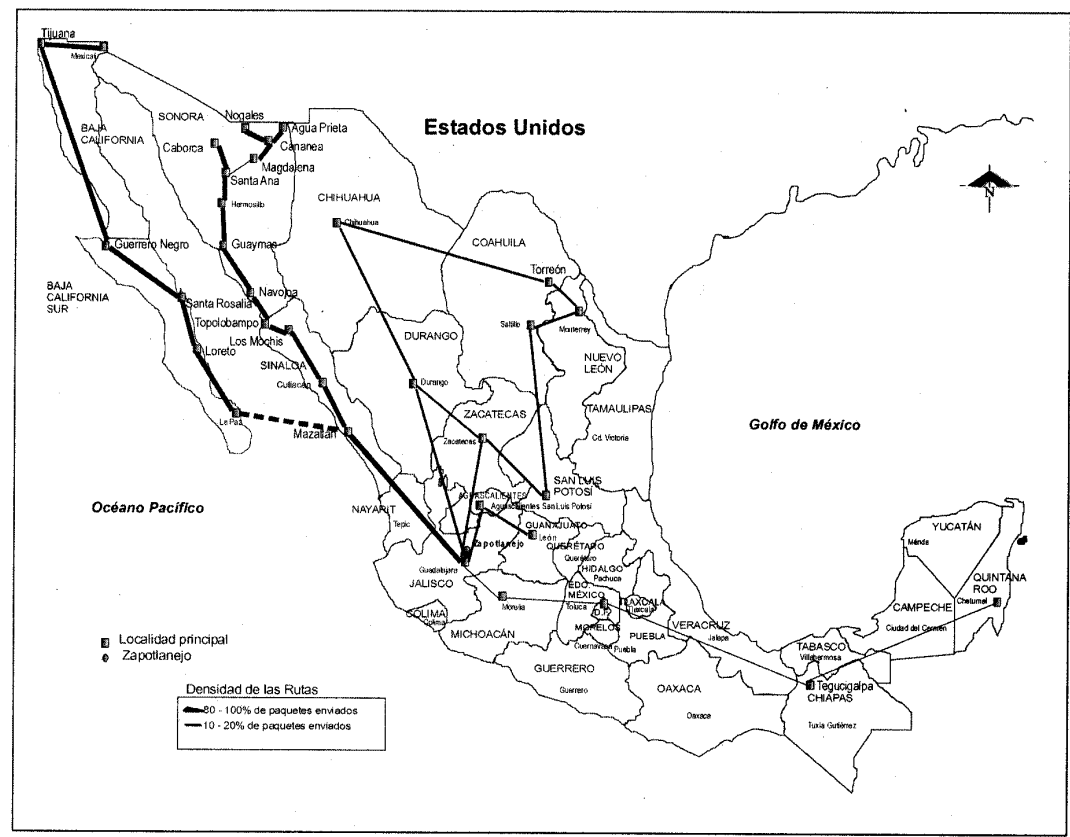

Mapa 3. Ruta comercial del vestido originada en Zapotlanejo, Jalisco, 2001.

Fuente: entrevista con gerentes de paqueterías, Zapotlanejo, agosto, 2001.

paquetería localizadas en Zapotlanejo remiten $80 \%$ de sus envíos hacia esas provincias, reforzando lo expresado anteriormente ( $C f$. Mapa 3).

Como estrategia de sobrevivencia, los fabricantes optan por la copia de nuevos modelos de ropa entre sus mismos competidores. Hay una férrea competencia entre ellos, situación que obliga a elaborar dos nuevos modelos por semana (entrevista con los fabricantes de ropa, agosto 2002). Ésta es su ventaja competitiva inmediata y para estar en la dinámica existe imitación intencional entre unos y otros, aparte de que acuden a los grandes almacenes de ropa como Fábricas de Francia, Suburbia, con el fin de copiar los modelos. ${ }^{7}$ Esta situación se presenta debido a que la moda está en constante cambio y las grandes tiendas son las primeras en traer las nuevas tendencias de estilo en la ropa. Además, las fábricas de Zapotlanejo, por la escala de producción, tienen la facilidad para reestructurarse constantemente: se trata de microempresas.

venden en pagos en sus localidades de origen. Existe una persona que organiza y promociona los viajes por medio de los avisos de ocasión de los periódicos El Debate, de Sinaloa, El Sudcaliforniano, de Baja California Sur, por ejmplo, es el caso del que sale por la noche de Sinaloa, Ilega a Zapotlanejo a las 2:00 pm y regresa el mismo día.

7 Lo ideal sería que se desarrollara en la localidad la innovación mediante el diseño, pero no existen escuelas especializadas en ello.

\section{Desar}




\section{c) Condiciones histórico-culturales y relaciones de confianza}

El hecho de que exista un distrito industrial no sólo depende de las condiciones técnicoproductivas y socioculturales, sino también de la creación y consolidación de una red estable de conexiones con los mercados finales, pues el distrito no es un hecho exclusivamente local, también lo es de reorganización del mercado. La dimensión de vitalidad de las pequeñas empresas es un factor sociocultural: las nuevas empresas son fundadas por personas de la localidad, lo cual representa un factor muy importante.

La organización a partir de iniciativas locales representa un elemento clave para el posterior desarrollo de la zona. Prueba de ello es la creación de una asociación denominada Grupo de los 100, cuyo propósito es la organización de las expomoda en la región y para pertenecer a él es indispensable ser de la localidad.

Los empresarios no sólo deben ser originarios del lugar, también deben apoyar al desarrollo de su región. La última plaza comercial que se construyó fue iniciativa de los empresarios de la localidad ante el problema del uso de los espacios.

El papel de la comunicación es determinante debido a que existe una relación en el proceso productivo, y la información necesaria para crear el tipo de prenda y cantidad requerida. La atmósfera industrial que se está desarrollando en Zapotlanejo incipientemente está facilitando la formación de trabajadores y empresarios en confección en un nivel empírico. La transmisión del conocimiento, basada en la costumbre, de padres a hijos.

Para Becattini, el caso de los distritos industriales representará un ejemplo de cuasi mercado, con la característica de que empresas localizadas ahí pertenecen a un mismo ciclo de producción y tienen un panorama general de las demás, sin que por esa razón se altere su funcionamiento. La segmentación en el mercado de trabajo puede tratarse de un fenómeno de naturaleza espacial, con ventajas comparativas cíclicas, pero no permanentes.

La ventaja radica en su estructura organizativa, más eficiente en situaciones de irregularidades de oferta y demanda que la de una estructura industrial integrada verticalmente. Zapotlanejo no puede ser considerado, propiamente dicho, un distrito industrial acorde con los parámetros encontrados en el modelo marshalliano o mejor dicho, italiano. Zapotlanejo tiene su dinámica de desarrollo y, por lo tanto, presenta sus propias características, es por ello que podría hablarse de distritos mexicanos. Según Guerrieri y Pietrobelli (2003:2), ninguno de los distritos industriales es estrictamente igual a otro, como se ha demostrado en cuanto a distintos productos especializados, grado de complejidad organizacional, sistemas de redes y el contexto social y cultural.

Para que el modelo de organización productiva de Zapotlanejo tenga continuidad y pueda ser considerado como uno de organización industrial, es fundamental desarrollar políticas públicas acordes con las necesidades de la zona.

Con lo anterior, es posible comprender la importancia que tienen los fenómenos de densificación localizada y de las relaciones entre industrias dotadas de una cierta estabili- 
dad, los cuales pueden constituirse como un modelo alternativo para la política industrial regional o local. Según Rabellotti (1997), pequeñas empresas locales de una sola planta muestran una racionalidad de localización diferente a la de grandes empresas multiplanta. Las primeras tienden a adoptar una estrategia conservadora en sus decisiones de localización. Los factores personales son determinantes, pues por lo regular eligen una localización familiar que reduzca la incertidumbre y los riesgos, y que de igual forma puedan resolver problemas concretos como es el uso del suelo urbano y evitar los conflictos gremiales, como es el caso de Zapotlanejo.

\section{Transformación de la base económica del municipio, 1930-2003}

En el caso de la producción de ropa en Jalisco, compuesta en su mayoría por la pequeña y mediana empresas, en los últimos 30 años se observa una descentralización fuera de la zona metropolitana de Guadalajara. La diseminación actual de la industria hacia el occidente de México puede considerarse parte de un modelo cíclico más fluido de cambio regional (Wilson, 1990:16).

Wilson (1990) encuentra que existe una especialización productiva entre las regiones. Dedicadas a la fabricación de ropa de algodón, pantalón de hombre, ropa de mujer y de niño, pueden identificarse en las localidades de Los Altos de Jalisco. Zapotlanejo, por su parte, responde a esta lógica expresada mediante la especialización en confección de prendas de vestir para dama; además — hoy por hoy_ es uno de los centros comercializadores de ropa más importantes en la región noroeste y norte.

En los inicios de la industria en Zapotlanejo, una parte del proceso de fabricación de ropa se hacía a máquina (ensamble y costura) y otra a mano (pegado de botón, bastillas y diferentes aplicaciones), posteriormente a la máquina recta se le fueron adaptando accesorios que suplirían las labores que antes eran manuales. Actualmente, todo el proceso está maquinizado, excepto el deshebrado y el empaquetado.

La evidencia empírica encontrada hasta el momento revela que el crecimiento económico de Zapotlanejo no responde a una política de planificación central, sino al resultado de iniciativas particulares de familias locales, que buscaron y encontraron una forma de aprovechar el capital social de la región, especializado en el deshilado, tejido y bordado de prendas.

En sólo medio siglo, observamos la trasformación de un municipio agrícola a uno dedicado a la actividad industrial y comercial ${ }^{8}$ (Gráfica 1). En 1940 tenía 18342 habitantes, cuya principal actividad económica estaba sustentada en la producción agrícola; la

8 En la actualidad, los trapiches para la molienda de la caña se han trasformado en parte de la estructura urbana y lo único que queda de ellos es sólo el nombre en una de las localidades. Los cañaverales a los alrededores de la ciudad de Zapotlanejo han desaparecido para dar paso a los estacionamientos, fábricas, tiendas y plazas comerciales de ropa.

\section{Desartoris}




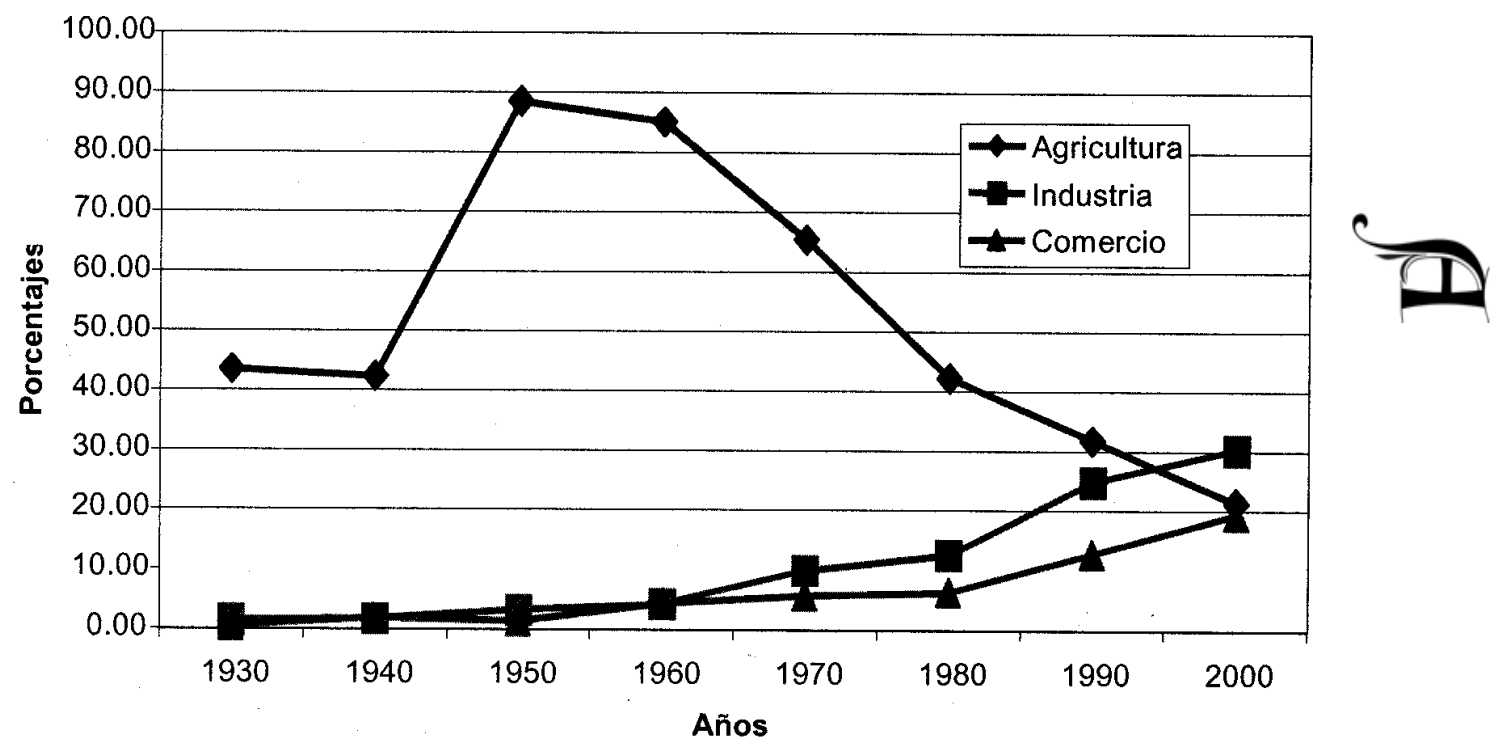

Gráfica 1. Población económicamente activa en las principales actividades económicas en el municipio de Zapotlanejo, 1930-2000.

Fuente: Censos de Población. INEGi. Varios años.

actividad manufacturera, por su parte, no era representativa. De acuerdo con el Censo de Población y Vivienda del mismo año, dentro del subsector textil laboraban diez personas (nueve hombres y una mujer).

En ese sentido, Arias y Wilson (1997:16-19) manifiestan que hubo ciudades de talla media que lograron eludir la fuerza centrífuga de la gran ciudad y recrear o mantener su tradición manufacturera. Durante muchos años se privilegió la noción de que la industrialización representaba una ruptura con la historia del trabajo de la sociedad rural. Mediante evidencia empírica, encuentran en Irapuato y Aguascalientes que la combinación de actividades forma parte integral de la tradición laboral de sociedad rural en algunas otras regiones de México.

Dentro del desarrollo económico de Zapotlanejo observamos tres etapas: la primera abarca de 1930 a 1970, cuando se presentan el auge, fortalecimiento y pérdida de importancia de la actividad agrícola y comienzan a surgir otras actividades económicas que rompen el esquema de la monoespecialización, como la industria, el comercio, la construcción servicios personales y los transportes.

La segunda etapa, de 1971 a 1995, despega con la actividad industrial, seguida del comercio, mientras que las labores agrícolas pierden importancia. La industria supera en importancia a la agricultura, conformándose así una nueva lógica de organización espacial, formas de invertir el capital acumulado en agricultura y, en adaptación de los trabajadores en otras ramas productivas. La industria ocupa una posición cada vez más importante. 
En la tercera etapa, de 1995 a la fecha, se calcula que el comercio supera a la agricultura, al igual que lo hizo la industria en la etapa anterior. También se espera que los servicios (bancarios, hoteles, restaurantes) sigan desarrollándose a la par del auge industrial y comercial, la localidad, al ser un polo de atracción para fabricación y venta de ropa, provoca que a los visitantes se les tengan que proporcionar los servicios necesarios, por lo que tienen que cumplir con estándares de calidad cada vez mayores.

Actualmente la población económicamente activa ocupada dentro del sector primario representa $21.17 \%$, porcentaje tres veces inferior al del sector secundario y terciario juntos. El secundario incrementó su participación en 25 puntos porcentuales con respecto de 1970, y su mayor dinamismo se presentó en el periodo 1980-1990, con un incremento de 17\%.

Dentro de este sector, la industria manufacturera representa el mayor dinamismo, en los últimos veinte años incrementó 20 puntos porcentuales su participación dentro de la PEA ocupada. Actualmente proporciona empleo a 30\% (5 955) del total de trabajadores del municipio de Zapotlanejo. El periodo de mayor auge se presenta entre los años ochenta y noventa, a pesar de las condiciones macroeconómicas adversas, materializadas en las continuas devaluaciones. Los empresarios locales han sabido sortear esas dificultades por medio de mecanismos que se han construido dentro del núcleo familiar. Entre estas estrategias figura la construcción de redes sociales, expresadas mediante el otorgamiento de créditos con tasas de interés muy bajas e incluso nulas entre parientes, situación más frecuente entre padres e hijos. También existe el préstamo de maquinaria cuando alguno de los integrantes de la familia empieza en el negocio de fabricación de ropa.

El dinamismo industrial y comercial de la zona produce incrementos superiores en demanda de fuerza de trabajo a la existente en el municipio. Esta situación genera una diferenciación selectiva de trabajadores respecto del lugar de procedencia y grado de escolaridad. La evidencia empírica encontrada hasta el momento nos muestra dos patrones selectivos de la fuerza de trabajo: $a$ ) la población de pueblos contiguos a la localidad de Zapotlanejo se emplea principalmente como obreros en talleres de fabricación de ropa y como empleados en las tiendas comerciales; $b$ ) los trabajadores de la Zona Metropolitana de Guadalajara — principalmente— como encargados de tiendas (proveedoras de telas, maquinaria e insumos).

La movilidad de la fuerza de trabajo en Zapotlanejo responde a las necesidades del mercado. Esto quiere decir que hay temporadas en las cuales se tiene que hacer recorte de personal e, inclusive, cerrar algunos talleres, tiendas y proveedurías debido a que las ventas son mínimas y los gastos fijos pueden llegar a superar la relación ingreso-gasto y generar pérdidas.

\section{Características de la industria del vestido en Zapotlanejo}

En lo referente a esta industria, el caso de Zapotlanejo presenta connotaciones sui generis, es decir, muy particulares a esa región, las cuales obedecen a condiciones locales, cons- 
truidas a partir de la configuración económica, histórica y social imperante a lo largo de los últimos 30 años. Entendiendo por configuración el conjunto de elementos tanto externos como internos que conforman un ordenador y hacen que destaquen las peculiaridades que tiene Zapotlanejo actualmente en torno a la industria del vestido. Dentro de las características propias de la zona podrían mencionarse seis:

a) Una serie de aspectos relacionados con habilidades en la confección de prendas de vestir, como resultado de una tradición femenina del bordado y deshilado en la zona de Los Altos de Jalisco, como lo documentaron Arias y Wilson (1997:206-207).

b) Aspectos antagónicos relacionados con una cultura individualista en la que, al mismo tiempo, se procura construir y mantener redes de cooperación tanto sociales como empresariales, formales o informales.

c) Las formas de apropiación del conocimiento mediante la comunicación de padres a hijos en la creación de mecanismos para la comercialización y producción de ropa.

d) La capacidad de incorporación al sector más dinámico de la industria del vestido, en producción de prendas de moda con bajos costos, mediante una variedad de productos.

e) La destreza para vincularse al ámbito regional por medio de la comercialización de prendas hacia la región norteña.

f) La habilidad para convertirse y difundir su imagen y circuitos alternativos de mercado popular.

Aunque el factor que puede ser más importante para el desarrollo de Zapotlanejo es la devaluación del peso, a partir de los años ochenta, la importación de prendas de vestir de Estados Unidos - comúnmente dirigida a los mercados de clase media de estados del norte- resultó inaccesible y hubo que mirar hacia el interior del país. Zapotlanejo y Guadalajara son dos centros productores de ropa mejor conectados y más cercanos por la infraestructura carretera a la región del norte.

Durante el primer quinquenio de los años ochenta se inició el boom de la confección de ropa en Zapotlanejo. La momentánea estabilidad del mercado cambiario favoreció la situación. Pero a raíz de la crisis de 1986-1987, se observó un desplome de producción de ropa en la localidad, originado por la crisis económica, contrario a lo que sucedió a la población ocupada y número de establecimientos. Ante esta situación de crisis, los trabajadores se vieron en la necesidad de autoemplearse por medio de la creación de pequeños negocios, los cuales se incrementaron entre 1986 y 1988 y presentaron un comportamiento atípico ante las otras variables estudiadas. ${ }^{9}$

A partir de 1988 y a pesar de recurrentes crisis devaluatorias (Gráfica 2), durante las dos últimas décadas del siglo pasado la industria de ropa en Zapotlanejo no sólo se mantuvo

9 En todos los ámbitos, se observa que las empresas informales se desarrollan cuando se presentan las crisis económicas, debido a la necesidad del autoempleo. 


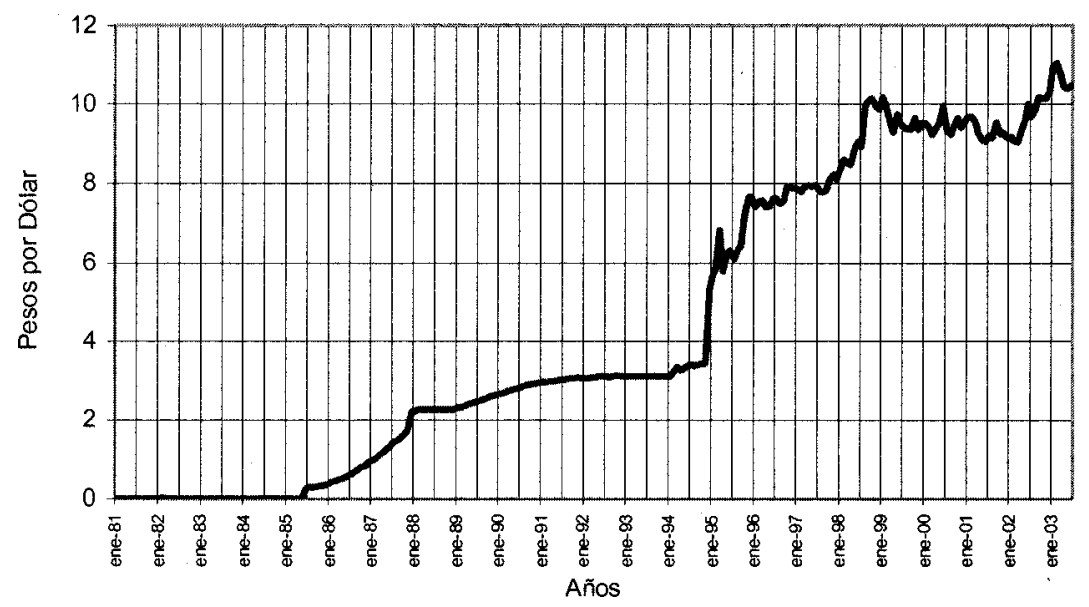

Gráfica 2. Paridad peso-dólar (fluctuaciones de la moneda mexicana, 1982-2003.

Fuente: Banco de México. Indicadores Económicos, 2003

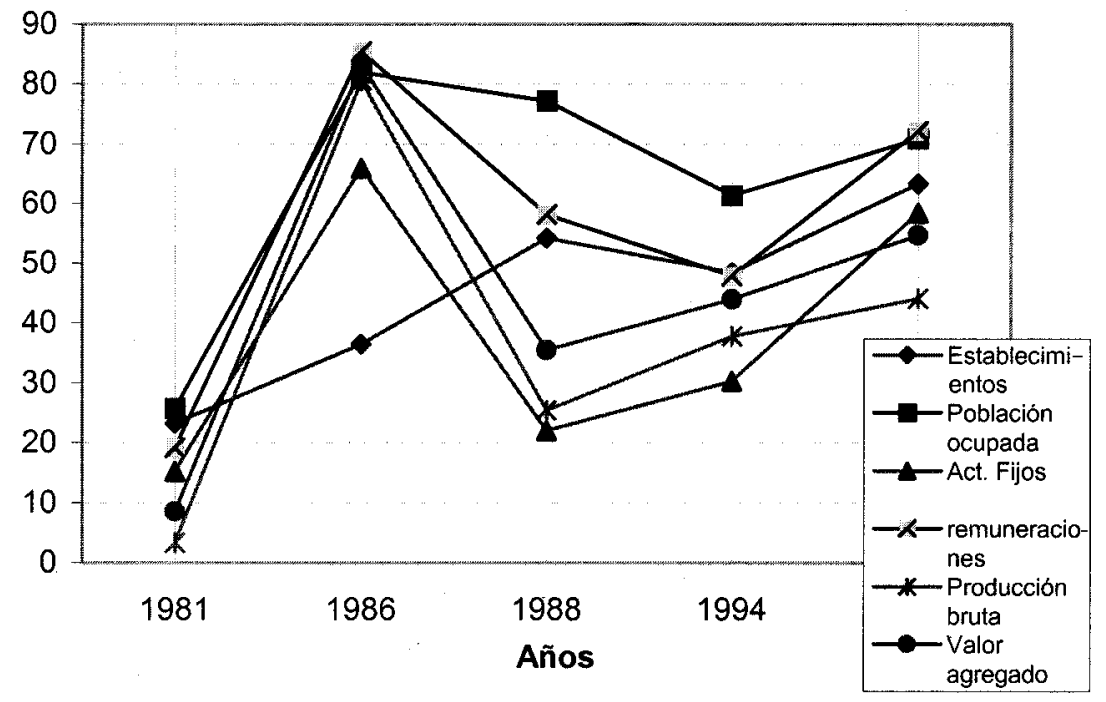

Gráfica 3. Participación porcentual del subsector textil con respecto al total de la manufactura de Zapotlanejo, 1981-1998.

Fuente: elaboración propia con base en los Censos Económicos, 1981-1999, INEGII. 
e incrementó su presencia (Gráfica 3 ) en cuanto a la población ocupada y al número de establecimientos, también modernizó su maquinaria con el mayor ritmo de crecimiento que presentaron sus activos fijos en relación con otras variables analizadas.

Al estudiar la paridad del peso frente al dólar y la participación porcentual de industria de ropa en Zapotlanejo — dos últimas décadas del siglo anterior- encontramos cuatro etapas de desarrollo: a) 1980-1985, despegue de industria con un mercado cambiario relativamente estable; b) 1985-1988, desplome en variables de producción bruta, activos fijos y valor agregado, se presenta la llamada crisis de los ochenta en la devaluación del peso; c) 1988-1993, recuperación de la industria del vestido en un contexto macroeconómico sin grandes sobresaltos, es decir, más o menos estable; y d) 1993-1998, despegue a pesar de la crisis crediticia, la abrupta devaluación de 1995 (el peso se cotizaba en 5.7 y pasó a 7.6 pesos por dólar), la apertura comercial y la inminente introducción de prendas de vestir de contrabando de origen chino.

Las crisis financieras han golpeado fuertemente a Zapotlanejo; ahora se encuentra ante un nuevo tipo de crisis derivada del contrabando, importación de ropa usada y comercio desleal (dumping), este último impulsado principalmente por los chinos. Una situación que está proliferando es el rompimiento de vínculos fábrica-talleres de maquila, ya que las primeras optan por convertirse en comercializadoras de prendas.

Zapotlanejo pudo hacer frente a situaciones externas con relativa facilidad debido a la organización industrial de la producción de ropa, basada principalmente, en la proliferación de micro y pequeñas empresas y en las estrategias de cooperación adoptadas mediante: $a$ ) el uso de prestamistas locales ${ }^{10}$ - los cuales, pese a manejar tasas de interés elevadas (3 y $8 \%$ mensuales) son una opción dentro del mercado crediticio- - y $b$ ) los créditos de los proveedores. Es decir, no funciona el sistema bancario para impulsar y desarrollar al tejido industrial local, entonces, los fabricantes crean sus propias alternativas ante el nulo apoyo de instituciones.

\section{Estructura de la planta productiva}

Con base en una encuesta ${ }^{11}$ aplicada a 19 empresas dedicadas a la industria de ropa en la localidad de Zapotlanejo durante 2001, se pudo recabar información referente a la organi-

10 A pesar de los al tos intereses que pudieran cobrar prestamistas locales, esta situación les ha permitido salvaguar darse dela crisis del mercado crediticio en M éxico. Al sistema de préstamos locales solamente pueden acceder los familiares del prestamista o personas "muy conocidas, desde hace años". (Entr evista con seis personas que actualmente prestan dinero a rédito, 12 de septiembre de 2003, Zapotlanejo).

11 Este trabajo es parte otro más amplio y corresponde a una tesis doctoral - que actualmente se desarrolla- acerca de la reestructuración productiva y redes en la industria de la confección. Su objetivo es analizar la conformación de las redes sociales de producción en la industria del vestido en Zapotlanejo, a partir de cómo las construyen actores, y su funcionamiento. Para ello, primero se construyó empíricamente la industria del vestido, se caracterizaron las redes comerciales y de 
Cuadro 1

Fábricas entrevistadas en la localidad de Zapotlanejo

\begin{tabular}{ccl}
\hline Nombre* $^{*}$ & Año de fundación & \multicolumn{1}{c}{ Tipo de productos } \\
\hline A & 1999 & Confección de blusas y pantalones para dama \\
B & 1996 & Confección de blusas y conjuntos para dama \\
C & 1997 & Confección de blusa y pantalón para dama \\
D & 1991 & Confección de pantalón, vestido y blusa para dama \\
E & 1968 & Confección de blusa camisera, blusa de punto y pantalón de vestir para dama \\
F & 2000 & Importadora de prendas de vestir para dama \\
G & 1981 & Confección de pantalón, blusa y conjunto para dama \\
H & 1985 & Confección de blusa, pantalón y conjunto para dama \\
I & 1985 & Confección de blusas, faldas y pantalones para dama \\
J & 1989 & Confección de falda, blusa, short y pantalón de mezclilla para toda la familia \\
K & 1989 & Confección de camisas lisas y de cuadro \\
L & 1989 & Confección de prendas para bebé y tallas extras** \\
M & 1992 & Confección de pantalón, blusa y conjunto para dama \\
N & 1996 & Confección de short y pantalón para niña y dama \\
O & 1980 & Confección de ropa industrial (pantalones, camisas y overoles) \\
P & 1990 & Confección de vestidos y conjuntos para dama \\
Q & 1997 & Confección de pantalón para dama \\
R & 1999 & Confección de pantalón, blusa y chamarra para dama \\
S & 1997 & Confección de pantalón, falda y conjunto para niñas \\
\hline
\end{tabular}

* Se obviaron los nombres de la razón social para guardar el anonimato de las fábricas encuestadas.

** Se consideran tallas extras en Zapotlanejo aquellas que están por arriba de la talla 38.

Fuente: Encuesta Reestructuración productiva y redes en Zapotlanejo, 2001.

zación empresarial, específicamente acerca de cuáles han sido las estrategias adoptadas en los últimos años para enfrentar la competencia ${ }^{12}$ (véase Cuadro 1).

En todos los casos, las fábricas se consideran uniplanta, es decir, su relación con los talleres, maquila a domicilio y otros sitios que son de su propiedad - como centros de lavado y procesado de la prenda - no tienen que ver con la planta principal. No ven como parte integral de su negocio a quienes hacen otras partes del proceso productivo, cuestión que responde a una estrategia para abaratar costos, pues se desligan del pago del Seguro Social, sueldos, prestaciones, renta para el local, maquinaria. En algunos casos, la fábrica es dueña de las máquinas, pero en su mayoría, los maquileros las compraron en abonos, y se subcontratan en la modalidad de destajo, en otras palabras, se paga por monto de prendas trabajadas (pegado de botón, bastilla, ojal, planchado). ${ }^{13}$

insumos, seidentificaron las estrategias que establecen los empresarios de la industria de la confección mediante la conformación de redes y, por último, se caracterizaron las redes sociales de producción.

12 Para el egir las empresas se tomó el padrón de permisos y licencias otorgadas por municipio y la lista de participantes en una feria de industria de la ropa organizada en Zapotlanejo. Se hizo una selección de entre todos los fabricantes y se eligió a 34 fábricas, a las que se invitó, no una, sino hasta cinco veces. Al final, solamente contestaron 19.

13 Pagan en promedio de 10 a 12 pesos por prenda confeccionada (pantalón y falda $\$ 10$, blusa $\$ 6$ y $\$ 15$ con ensamble). En el pegado de botón se pagan 10 centavos por cada uno (cada camisa lleva seis). Al día, un obrero puede pegár selos a 100 camisas y estaría ganando 60 pesos diarios, es decir, cerca de dos salarios mínimos (observación directa con los maquileros, septiembre de 2002).

\section{Desaar ron}


Los meses en los cuales tienen mayor demanda de trabajo los talleres y la maquila a domicilio son octubre, diciembre y mayo, se aminora durante julio y agosto. En entrevis$\operatorname{tas}^{14}$ realizadas a personas que se dedican a maquilar prendas, se encontró que las máquinas son de su propiedad y fueron adquiridas en abonos, sólo en un caso se adquirieron al contado - ya usadas - con un familiar. La periodicidad con que reciben los cortes es semanal y cosen un promedio de 300 a 600 prendas. Los cortes están encadenados, es decir, que antes de terminar la semana ya tienen el siguiente trabajo, de esta manera no dejan de funcionar las máquinas ni las personas de laborar.

El vínculo de trabajo se efectúa por medio de la relación de parentesco y amistad. Su jornada de trabajo es de ochos horas, de lunes a viernes, y no cuentan con ninguna seguridad social, el negocio no está registrado ni pertenecen a ninguna asociación relacionada con la industria del vestido. Esta forma de organización del trabajo siempre ha existido y nunca ha tenido problemas, porque las autoridades saben que existen y en palabras del secretario particular del presidente municipal: "resultaría perjudicial tratar de regularlos, ya que son una fuente importante de ingresos para las familias de la zona, y es que en Zapotlanejo cada casa es un taller".

\section{Estrategias empresariales}

Las plantas estudiadas representan un volumen de ventas anuales que van de $\$ 500000$ hasta 120 millones de pesos. En realidad, la primera cifra representa una cantidad muy baja, correspondería a 12000 pesos mensuales, incluso ssi lo contrastamos con las rentas que pagan en sus locales de venta (de 80000 pesos a 100000 anuales) más los sueldos que pagan a los empleados (entre 600 y 900 pesos semanales).

Los encuestados plantean que las ventas han bajado considerablemente, en relación con 1998 y años anteriores, debido a la ropa que entra al país procedente de China y a la de Estados Unidos, ${ }^{15}$ que se venden en los tianguis de la Zona Metropolitana de Guadalajara a precios muy económicos. Así también, durante la crisis económica que se presentó a finales de 1994, la gente no tenía dinero en efectivo para gastar, lo cual redujo la demanda de ropa, no obstante, sobrevivieron.

14 Se hicieron tres entrevistas: a dos personas que trabajan maquila a domicilio y al dueño de un taller de maquila. El tiempo requerido fue de 30 minutos a una hora y se llevaron a cabo en la localidad de Zapotlanejo los días 6 y 8 de mayo de 2002.

15 La ropa usada es comprada por kilo en Estados Unidos, el comprador no puede escoger las prendas porque están apiladas en pacas. Viene todo tipo de ropa: para niños, grandes, hombres, y mujeres, y en muchos de los casos se encuentra saldos de ropa aún con etiquetas (entrevista con un comerciante del Tianguis del Sol, Guadalajara). Esta forma de comercialización de ropa no es exclusiva de Jalisco. En M azatlán, Sinaloa, se encontró evidencia - por medio de un anuncio en el periódico El debate, 31 de octubre de 2001, p. 26-A- en la cual se invita a los mayoristas a comprar pacas de ropa usada procedente de Estados Unidos y tenis de marca pisados - son ten is nuevos que tienen algún pequeño defecto después de haberse usado- a precios económicos. 
Dichas plantas muestran poca o nula participación en las exportaciones, se orientan principalmente hacia el mercado interno, debido a dos situaciones: $a$ ) es necesario manejar grandes volúmenes de producción, y b) malas experiencias, al no conocer los mecanismos de exportación.

Últimamente se observa un incremento en el número de negocios dedicados a la compraventa de ropa importada de Estados Unidos y China, lo cual ha repercutido en el nivel de ventas y de esta forma se propicia la competencia desleal. Tal es el caso de las personas que piratean la marca — compran telas parecidas-, y es difícil distinguir cuál es original. Esto ha generado el surgimiento de negocios con una gran flexibilidad de adaptación a los cambios de productos y accesorios copiados de marcas conocidas.

Existen fábricas que en realidad son comercializadoras de productos importados, una mínima parte del total de prendas que manejan son confeccionadas por ellas. Y la tendencia que manifiestan es a convertirse exclusivamente en importadoras.

Esta tendencia, en gran medida compite con las prendas fabricadas en la localidad y se expresa mediante pirateo $^{16}$ de modelos y tendencias de moda de las importadoras.

A pesar de estos problemas, los empresarios adoptaron algunas estrategias con el fin de tener presencia en el mercado, entre las que figuran:

1. Ferias y exposiciones nacionales e internacionales, con el fin de estar a la vanguardia en los nuevos conceptos de moda ( $80 \%$ de los entrevistados).

2. Para financiar la producción y no recurrir a bancos que manejan altas tasas de interés,se manejan mediante créditos en insumos con sus proveedores.

3. Prestamistas locales, junto con proveedores de insumos se han convertido en la principal fuente de financiamiento local.

4. En $100 \%$ de los casos la familia (padres, hermanos) cuenta con otros negocios, y se hacen préstamos entre sí, ya sea en maquinaria, dinero, insumos, trabajadores, entre otros, dependiendo de las necesidades de cada uno.

5. Cerca de la mitad de los encuestados piensa ampliar su capacidad instalada, con el fin de introducir nuevos productos.

6. Solamente $10 \%$ piensa en establecer alianzas con productores nacionales o extranjeros.

7. En la localidad no existe una cultura del establecimiento de los contratos firmados. Más de $95 \%$ de los entrevistados realiza sus operaciones mediante acuerdos verbales, respaldados en la amistad y el parentesco.

8. Los apoyos gubernamentales no han tenido el impacto esperado en Zapotlanejo. 90\% de los entrevistados no sabe de la existencia de algún programa de ayuda, otro 10\%, cuando han intentado solicitarlos enfrentaron los siguientes obstáculos: $a$ ) exceso de documentos solicitados; $b$ ) dificultad para encontrar los avales en la solicitud de créditos; c) altas tasas de interés manejadas en los préstamos.

16 El tiempo para copiar una prenda es mínimo. Durante las entrevistas, fabricantes y diseñadores coincidieron en que se necesitan unas cuantas horas para sacar el molde, sólo es cuestión de observarlo.

\section{Desartoris}




\section{A manera de conclusión}

- Las economías de aglomeración, presentes en los centros especializados, traen beneficios en un primer momento, posteriormente generan conflictos en la lucha por el espacio. En Zapotlanejo se observan algunos: altos costos en las rentas, falta de empleados, robos, saturación de las calles, falta de estacionamientos y reducción del tamaño de las tiendas, entre otros. Hoy, esta localidad se está consolidando como un importante centro productor y comercializador de ropa.

- Las redes sociales y empresariales en Zapotlanejo se integran local, regional e internacionalmente y son construidas por los individuos a partir de intereses comunes. Las instituciones gubernamentales no participan dentro del proceso. Las redes empresariales se ven plasmadas en las relaciones: proveedor-fabricante, fabricante-maquilador, fabricante-comprador mayorista, comprador medio mayoreo-menudeo. El elemento fundamental del desarrollo de la industria del vestido en Zapotlanejo se encuentra en el fortalecimiento de redes familiares, de amigos y por intereses comunes.

- La formación y ampliación de las redes se encuentran asociadas a acuerdos informales, en los cuales la cooperación y la solidaridad del círculo de amigos y familiares están presentes. Cuando existe gran cantidad de trabajo se apoyan unos a otros para sacarlo en el tiempo determinado, sin que se les tengan que pagar horas extra. También, cuando es temporada baja, el fabricante opta porque se trabajen tres o cuatro días a la semana. Tiene doble propósito: que la gente no se quede sin trabajo y pueda tener dinero para comer, así como una estrategia para que no busquen otro empleo, pues según los entrevistados, existe mucha dificultad para encontrar personal de confianza.

- Existe una fragmentación espacial del proceso productivo, materializado por medio de los talleres y maquila a domicilio, ubicados en localidades y ranchos contiguos a la cabecera municipal de Zapotlanejo. En algunos casos, esta descentralización sobrepasa los límites políticos del municipio y se prevé que esta tendencia siga manifestándose en los próximos años.

- Actualmente se está conformando un patrón de demanda de productos dirigidos hacia la zona del Pacífico (Sonora, Nayarit, Sinaloa, Baja California Norte y Baja California Sur) y Norte (Nuevo León, Saltillo, Chihuahua y Tamaulipas). Los vínculos de comercialización hacia estos lugares se crean a partir de iniciativas personales muy focalizadas.

- Existe una multiplicidad de canales de comercialización — debido a la gran demanda de mercancías - mediante tiendas de fábrica, creación de modernas y funcionales plazas comerciales, tianguis, comercios independientes, ventas por Internet, ventas por teléfono, ferias y exposiciones organizadas por los mismos empresarios.

- La producción y comercialización han creado una red de relaciones práctica y eficiente entre las diversas localidades especializadas en la fabricación de ropa. Para el caso de la producción, el ámbito de influencia se encuentra circunscrito principalmente hacia el interior del estado. Zapotlanejo es uno de los principales abastecedores de ropa de Villa Hidalgo y Moroleón, localidades que tradicionalmente se han caracterizado por la 
manufactura de prendas de vestir. En cuanto a la comercialización, ésta sí que rebasa los límites estatales y hasta nacionales.

- Las relaciones comerciales no sólo se circunscriben a la venta de ropa, sino que también intervienen en la compra de maquinaria especializada, telas, insumos y asistencia técnica. La tendencia actual de los proveedores es ubicarse en la localidad debido a que existe una férrea competencia y la contigüidad les permite responder a las necesidades inmediatas de sus clientes en tiempo y forma.

\section{Bibliografía}

Arias, Patricia y Fiona Wilson, La aguja y el surco. Cambio regional, consumo y relaciones de género en la Industria de la Ropa en México, Guadalajara, Universidad de Guadalajara-Centro de Estudios Estratégicos para el desarrollo, CUCSH, 1997.

Becattini, Giacomo, "The Marshallian Industrial District as a Socio-Economic Notion", en F. Pyke, G. Becattini and W. Sengerberger (editores), Industrial Districts and Inter-firm Cooperation en Italy, Génova, International Studies for labour Studies, 1990.

, "Los distritos industriales y el creciente desarrollo italiano" en Revista Sociología del Trabajo, núm. 5, Valencia, Siglo XXI, 1989, pp. 3-18.

_, "El distrito marshalliano: Una noción socioeconómica", en Benko y Lipietz (editoes), Las regiones que ganan: Distritos y redes. Los nuevos paradigmas de la geografía económica, Valencia, Alfons el Magnim, 1994, pp. 39-58.

Bellandi, Marco, "El distrito industrial en Alfred Marshall", en Revista Estudios Territoriales, núm. 20, Valencia, 1986, pp. 31-44.

Benko, George y Alain Lipietz, "De las redes de distritos a los distritos de redes", en Benko y Lipietz (editores), Las regiones que ganan: Distritos y redes. Los nuevos paradigmas de la geografía económica, Valencia, Alfons el Magnim, 1994, pp. 365-374.

Canullo, Giuseppe, "Los distritos industriales de las Marcas, Italia: Evolución y perspectivas”, en Alba Carlos, Bizberg Ilan y Hélene Riviere (compiladores), Las regiones ante la globalización, México, CEMCA, ORSTOM, COLMES, 1998, pp. 591-618.

Caravaca, Inmaculada, "Crisis, industria y territorio", en Ería, núm. 19, Oviedo, 1991, pp. 9-21.

Cota Yáñez, María del Rosario, Reestructuración y redes productivas en la industria de la ropa en Zapotlanejo, Jalisco, 1994-2003, tesis doctoral, Universidad de Guadalajara, 2004, pp. 333.

Crewe, Louis, "Material Culture: embedded firms, organizational networks and the local economic development of a fashion quarter", en Regional Studies, vol. 30, núm. 3, 1996, pp.13-21.
Guerrieri, Paolo y Carlos Pietrobelli, "Industrial districts evolution and technological regimes: Italy and Taiwan", en Technovation, Published by Elsevier Science Ltd., 2003 (version electrónica), pp. 1-15.

Instituto Nacional de Estadística Geografía e Informática (INEGI, IX, X, XI y XII Censos Generales de Población y Vivienda, 1970, 1980, 1990 y 2000, Aguascalientes.

Meyer-Stamer, Jorg, "Estrategias de desarrollo local y regional: Clusters, políticas de localización y competitividad sistémica", en Mercado de Valores, México, Nafinsa, septiembre, 2000, pp. 18-31.

Marshall, Alfred, Principles of Economics, Mcmillan and Co. Ltd., consultado en internet: http:// www.econlib.org/cgi-bin/cite.pl. The Library of Economics and Liberty, 1920.

Pietrobelli, Carlo, La articulación productiva en América Latina: Tipologías y políticas de fomento, Universidad de Roma, Ponencia presentada en el seminario Iberoamericano Iberpyme, Guadalajara, Jalisco, 13-15 de octubre del 2003.

Porter, Michael, The Competitive Advantage of Nations, London, Macmillan, 1990.

Quintar, Aída y Francisco Gatto, "Distritos industriales Italianos: Experiencias y aportes para el desarrollo de las políticas industriales locales", Documento de trabajo PRIDRE,núm. 29, Buenos Aires, CEPAL, 1992, pp. 76.

Rabellotti, Roberta, External Economies and Cooperation in Industrial Districts. A comparison of Italy and México, London, Macmillan Press LTD, 1997, pp.213.

Saba, Andrea, El modelo italiano: la especialización flexible y los distritos industriales, Santiago de Chile, Instituto Latinoamericano y del Caribe de Planificación Económica y Social-ILPES, 1998, pp. 137.

Secretaría de Industria y Comercio, Censos de Población y Vivienda, México, Dirección General de Estadísticas, 1900 -1960.

Wilson, Fiona, De la casa al Taller, Zamora, El Colegio de Michoacán, 1990.

\section{Desartor}

